Teresa A. Fishel

\title{
Learning advocacy for creating change through an immersion program Institute on Scholarly Communication delivers essential training
}

I n March 2006, Andrew Kantor wrote an article in the online version of USA Today entitled "Net Writing New Chapter for Scientific Publishing." His position was that the younger generation will be one of the driving forces in bringing about change in scholarly communication in the sciences. He states:

"[w]hat's going to happen is that more scientists, especially younger ones, will begin self-publishing their results before they bother to write a formal paper. They'll put them on their websites or blogs to solicit comments, and turn science into a conversation the way only modern technology allows."

Of course, "conversations" take place in all disciplines within their scholarly journals, thus the possibility of change is not limited to scientific publications. The rate of change may vary by discipline, but change is inevitable. It is in these changes to electronic publishing and scholarship that we may find solutions to the perceived crisis in scholarly communication. The idea that a networked environment will lead to change in scholarly publishing is not new. SPARC, which began in 1997, has used this theme on its Web site "Create Change." However, Kantor's article provides a starting point for a conversation that should be taking place on all campuses. If, as Kantor points out, the younger generation will drive change in scholarly communication, it is in the library's interest to leverage the enthusiasm for new publishing methods likely to be embraced by the younger faculty to guide the tenured faculty to new ways of thinking about scholarly publishing. To facilitate this dialogue, librarians must be able to articulate the issues in a language that will resonate with all faculty members.

\section{Institute on Scholarly Communication}

Academic librarians' efforts to become advocates for changes to scholarly communication on their campuses would benefit from adopting the same methods and fervor used for information literacy. Information literacy has advanced significantly through national and regional immersion programs by providing tools for librarians to articulate the need for information literacy and to develop local programs. Thus it is welcome news that librarians now have an immersion program for scholarly communication. The Institute on Scholarly Communication, cosponsored by ACRL and the Association for Research Libraries (ARL), should be considered essential training in effective advocacy for librarians and others, from all types and sizes of academic libraries and institutions.

The program designers built a collaborative model that encourages teams of participants drawn from a variety of academic personnel, mirroring some recent information

Contact Joyce L. Ogburn, series editor and cochair of the ACRL Scholarly Communication Committee, with article ideas, e-mail: joyce.ogburn@utah.edu

Teresa A. Fishel is library director at Macalester College, e-mail:fishel@macalester.edu

(c) 2007 Teresa A. Fishel 
literacy programs that have brought together librarians and faculty. As a participant in the first Institute on Scholarly Communication, I will share how it influenced our advocacy efforts at Macalester College.

In the spring of 2006, ACRL and ARL advertised a new, jointly developed Institute on Scholarly Communication. The two and one-half day immersion experience was intended to prepare participants to be local experts on scholarly communication issues, offering tools and skills to develop an outreach program tailored to their own campus environments. The institute was to provide a venue to:

"Work with experts in the field to understand how to better engage faculty at their institution around the crisis in the systems of scholarly communication. You will also learn about the emergence of new models for scholarly communication as well as strategies for creating systemic change."

My group from Macalester was particularly interested in the objectives of engaging faculty in discussion, becoming more informed about new models, and developing strategies for change. I wanted the skills to craft a new message that transcended the issue of escalating prices for journals to include possible solutions. The institute promised an enticing opportunity to learn how to engage our faculty, enlist them as advocates, and include them in the solution. The institute had clear and focused goals, and seemed to ensure that participants would come away with practical strategies and an achievable plan of action.

The first Institute on Scholarly Communication was held at the University of California-Los Angeles, July 12-14, 2006. Librarians, faculty, information technologists, and others comprised the 100 individuals accepted from universities and colleges. Our team consisted of me (library director), an associate library director, and our director for the center for scholarship and teaching (CST), who is a member of our faculty. ${ }^{3}$ CST is located within the library and the CST director has been a major ally in a number of library initiatives, including our information literacy program. With her participation, we expected to garner the help of at least one faculty advocate in outreach.

Prior to attending the institute, we completed a series of three exercises to help us prepare: 1) writing a brief introduction of ourselves, 2) preparing an environmental scan of our campus engagement in scholarly communication issues, and 3) developing a set of priorities for our future outreach efforts. Though Macalester is not a large research institution, our faculty are prolific producers of scholarly articles; however, they are not generally aware of the problems that have evolved in scholarly publishing. We found that completing the environmental scan was an excellent opportunity to introduce our CST director to the key issues. The time spent discussing open access, coupled with our interest in helping faculty retain their copyrights for published articles, in-

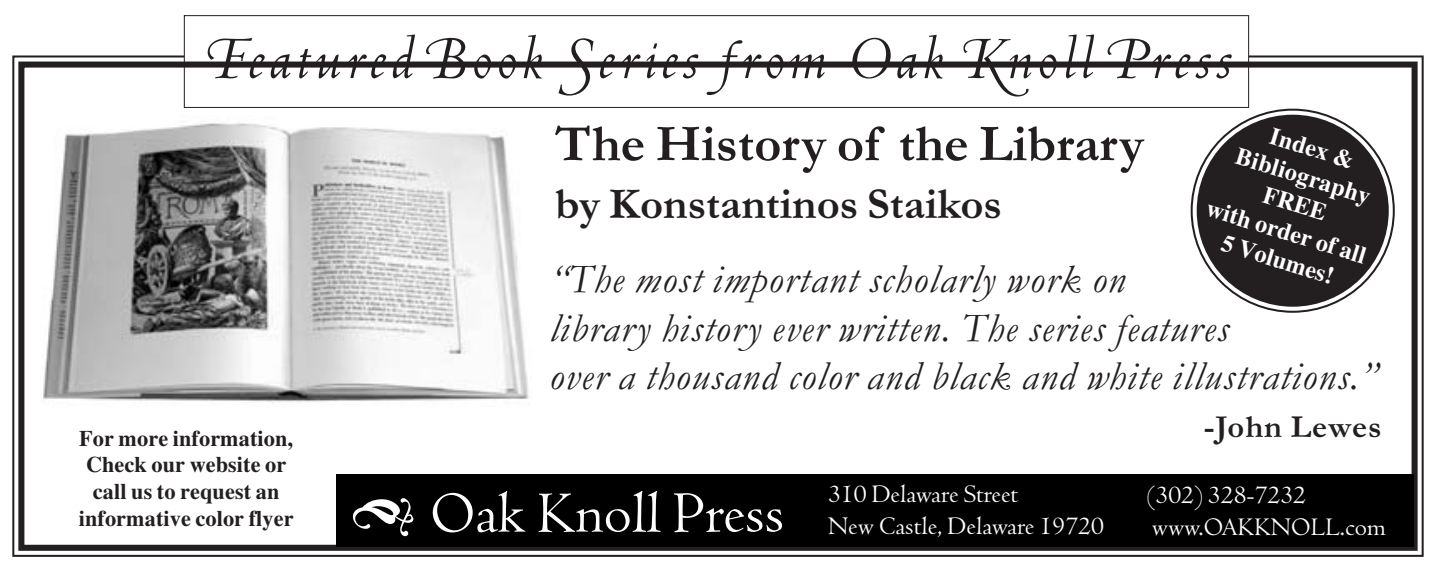


creased her awareness and understanding of the issues and what we hoped to accomplish by attending the institute. In addition to our written assignments, we were assigned a small number of readings to prepare for the institute. One very effective strategy was the use of a course management system for the institute. Through this system, we had access to the introductions of other participants and their environmental scans, and we gained familiarity with our cohorts before meeting face-to-face.

In a note sent to participants prior to the program, the institute faculty stated that they were: "Committed to creating a dynamic and valuable active learning experience." 4 We found that the faculty more than met their goal. The institute offered intensive but rewarding time for learning, conversation, and planning. A combination of lectures, exercises, and extended time for discussion with other participants fulfilled the "active learning experience."

We found two key exercises particularly engaging. First was an assessment of the publishing activity of a department on our campus. Through our assessment, we realized that although we could identify individual faculty members who were frequent contributors to scholarly journals, we knew very little about the specifics of their contributions or other related activities, such as serving on editorial boards. The assessment worksheet gave us a tool to start collecting specific data on faculty publications and to identify stakeholders with the potential to become faculty activists.

The second key exercise involved developing a "sound-byte" - a two-to-five-minute script to use when beginning conversations with faculty. It can often be difficult to engage faculty in meaningful discussions, especially if time with them is limited. It is essential to capture their attention, to really engage them as to why it is important that they be aware of the issues. We need to make explicit the implications inherent in changes to scholarly communication and what those changes might mean for research, teaching, and learning. The institute helped us to develop a message to deliver quickly and effectively. Fortunately we had a participant who is involved in public relations for her library. Her comments and contributions were invaluable to all participants. She cautioned us that if we continue to frame the conversation in library language, it will remain a library problem. ${ }^{5}$ It is essential that we find a way to articulate our message to faculty in a way that resonates with them.

We found that the mix of participants in the institute was an important aspect. Over the course of the institute, the conversations and discussions were enriched by the diversity of the group. The inclusion of crossfunctional teams effectively modeled the type of collaborative dialogue required to create change on our campuses. We collected many insights on how to frame the conversation. For example, early in the program, when we turned to legislative advocacy, the use of the acronym "FRPAA" led to some temporary confusion. To some participants, it meant the "Faculty Report on Professional Activities," to others it meant the "Family Rights and Privacy Act," and to only a few did it register as "The Federal Research Public Access Act." We were reminded frequently over the course of the program how language can be a barrier to our advocacy efforts.

Lastly, but most importantly and valuable, a major goal of the institute was for participants to prepare a customized program plan for their institutions. During the course of the institute, the guest speakers, in-class activities, and opportunities to share our insights with attendees from similar institutions all contributed to preparing each unique plan. Each team evaluated their campus and then applied what they learned to their own environment. We were able to engage in lengthy discussions that continued outside of the scheduled activities, which led to close connections among all the participants-another very positive outcome.

\section{Reflections on the first institute}

The experience of the team from Macalester 
shows that the first Institute on Scholarly Communication exceeded its stated goals and outcomes. We increased our knowledge of the issues, learned strategies for engaging our faculty, built relationships with our colleagues both on and off our campus, and developed a plan for outreach at our institution. The commitment of the organizers and faculty leaders produced a successful and dynamic learning experience. As I stated in a message to COLLIB-L, I had not previously experienced a workshop in which the energy level of the group increased over the course of the event rather than decreased. The effectiveness of the leaders, the structure of the program, and the variety of participants all contributed to an institute that was informative, practical, and extremely useful. The true test will be how effective the participants are on their campuses and if, over time, we can collectively and positively contribute to the changes coming to scholarly publishing.

A second institute was held at Duke University in December 2006, and at the 2007 ALA Midwinter Meeting, participants of the first two institutes will meet to share updates on how we have applied our new knowledge and skills. In the short period of time since completing the institute, we have accomplished quite a bit at Macalester. Upon returning to campus, we agreed that our first priority was to focus on increasing awareness. We held a forum for our library colleagues to share information on our experience. We developed "talking points" for library liaisons to use when meeting with departments to help increase faculty awareness. In the coming year we will develop a group of faculty and librarians who will prepare a comprehensive outreach program. I have met with the interim director for the center for scholarship and teaching, and, with her assistance, have identified and met with two faculty members who are interested in helping to achieve this goal. I have also met with our president and obtained his signature for a letter in support of FRPAA. ${ }^{6}$

As we all know, the function and ability of the academic library to provide access to scholarship have diminished over time. Changes in scholarly communication are going to happen, and they might provide solutions to our access problems. It is critical for academic libraries to be involved in leading change and developing campus programs that inform faculty and enlist new advocates. To do so, we require practical tools and effective strategies, along with the

\section{Apply for Institute on Scholarly Communication July 2007}

The Institute on Scholarly Communication uses a competitive application process. The number of participants is limited to 100 and both earlier offerings of the institute received more applicants than could be accommodated, so careful preparation is a good strategy.

The application is brief but requires a statement of goals and a letter of support from an administrator showing organizational commitment to the development of a scholarly communication program.The selection committee reviews the applications to create a cohort representing a wide range of professional backgrounds, types and sizes of institutions, and roles within the institu- tions. Team applications are encouraged, and teams that have included faculty have been especially successful.We recommend you review the report at www.arl.org/osc /institutes/isc/dec06report.pdf to help you prepare a strong application.

Find full details, including FAQs and online application, at www.arl.org/osc /institutes/isc.

Application available: Friday, January 19, 2007

Application deadline: Wednesday, March 14, 2007

Notification of status: Monday, April 16,2007 
help and commitment of other stakeholders on campus. In my experience, the Institute on Scholarly Communication provides the necessary tools and strategies, and encourages collaboration in a very successful immersion format.

ACRL and ARL plan to offer the Institute on Scholarly Communication at least once a year. I would strongly encourage every academic library director to form a team and make an application. With a third institute being proposed for the summer of 2007, now is not too soon to start preparing. ${ }^{7}$ To match the successful model for information literacy, my hope is that demand for the institute will lead to regional immersion programs, as well.

\section{Notes}

1. Andrew Kantor, "Net writing new chapter on scientific publishing" USA Today, www.usatoday.com/tech/columnist /andrewkantor/2006-03-23-net-science_x.htm.
2. ARL/ACRL Institute on Scholarly Communication, www.arl.org/osc/institutes/ isc/july06.html (accessed on November 4, 2006).

3. Our CST director participated in the preinstitute assignments, but the day prior to the start of the institute was informed of a serious health issue and was unable to attend the institute with us.

4. Note from faculty to participants, undated.

5. Judea Franck's "Remarks to Institute on Scholarly Communication Participants," July 13, 2006.

6. "53 College Presidents Lead Newest Show of Support for Public Access Act" Inside Higher Education, Sept. 7, 2006, www. library.uiuc.edu/blog/scholcomm/archives /higher_education/.

7. Complete details about the program are on the ACRL Web site Www.ala.org /ala/acrl/acrlissues/scholarlycomm /scholarlycommunication.htm. $z$

\section{Elegant Solutions for Preservation}

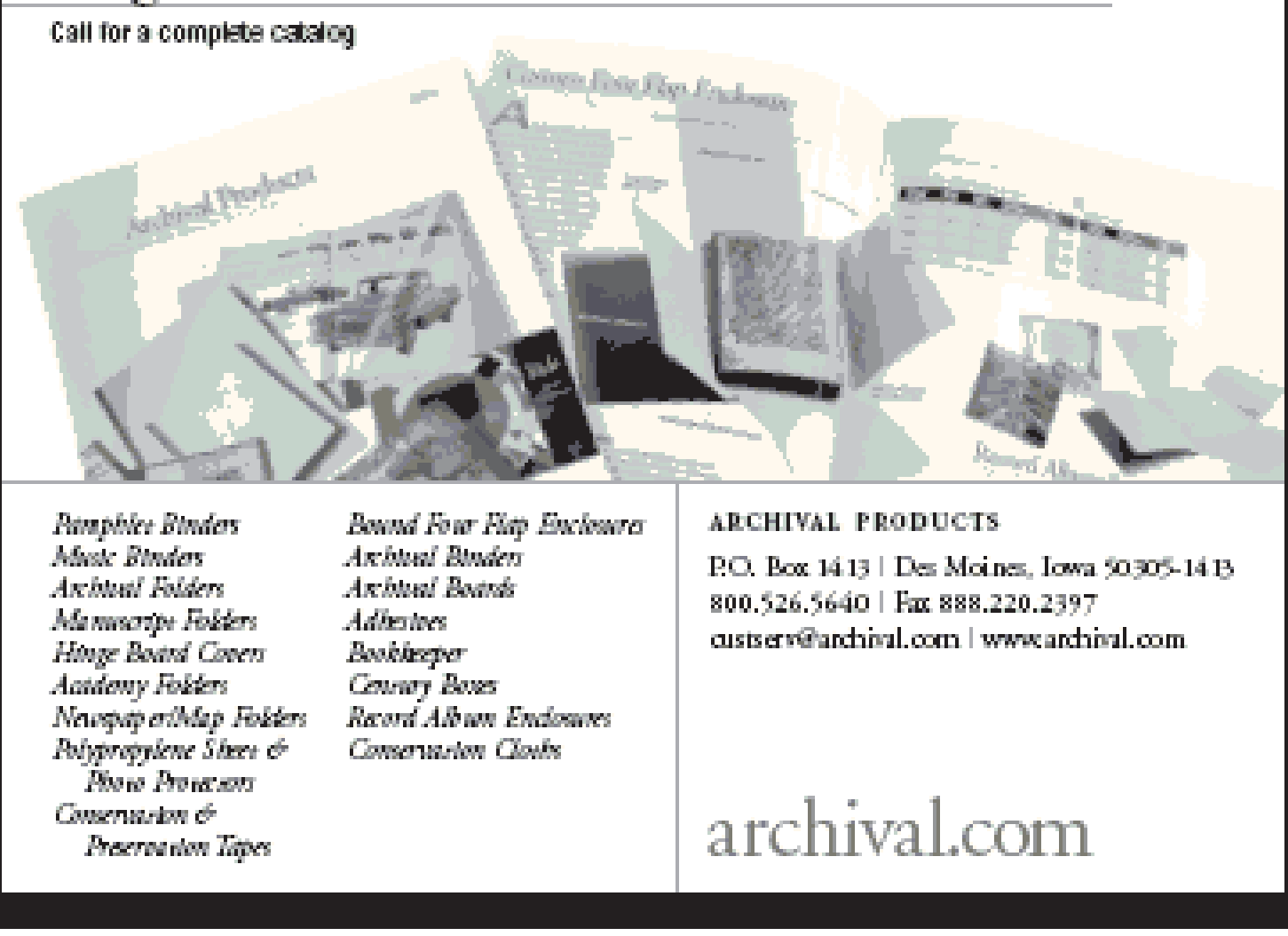

